\title{
Cold hardiness increases with age in juvenile Rhododendron populations
}

\author{
Chon-Chong (Kenny) Lim ${ }^{1}$, Stephen L. Krebs ${ }^{2}$ and Rajeev Arora ${ }^{1 *}$ \\ ' Department of Horticulture, lowa State University, Ames, IA, USA \\ ${ }^{2}$ David G. Leach Research Station of The Holden Arboretum, Madison, OH, USA
}

\author{
Edited by: \\ Michael Wisniewski, United States \\ Department of Agriculture - \\ Agricultural Research Service, USA \\ Reviewed by: \\ Lisa J. Rowland, United States \\ Department of Agriculture - \\ Agricultural Research Service, USA \\ Jason P. Londo, United States \\ Department of Agriculture - \\ Agricultural Research Service, USA \\ *Correspondence: \\ Rajeev Arora, Department of \\ Horticulture, lowa State University, \\ 139 Horticulture Hall, Ames, IA \\ 50011, USA \\ e-mail: rarora@iastate.edu
}

Winter survival in woody plants is controlled by environmental and genetic factors that affect the plant's ability to cold acclimate. Because woody perennials are long-lived and often have a prolonged juvenile (pre-flowering) phase, it is conceivable that both chronological and physiological age factors influence adaptive traits such as stress tolerance. This study investigated annual cold hardiness $(\mathrm{CH})$ changes in several hybrid Rhododendron populations based on $T_{\max }$, an estimate of the maximum rate of freezing injury (ion leakage) in cold-acclimated leaves from juvenile progeny. Data from $F_{2}$ and backcross populations derived from $R$. catawbiense and $R$. fortunei parents indicated significant annual increases in $T_{\max }$ ranging from 3.7 to $6.4^{\circ} \mathrm{C}$ as the seedlings aged from 3 to 5 years old. A similar yearly increase $\left(6.7^{\circ} \mathrm{C}\right)$ was observed in comparisons of 1 - and 2-year-old $\mathrm{F}_{1}$ progenies from a $R$. catawbiense $\times R$. dichroanthum cross. In contrast, $\mathrm{CH}$ of the mature parent plants ( $>10$ years old) did not change significantly over the same evaluation period. In leaf samples from a natural population of $R$. maximum, $\mathrm{CH}$ evaluations over 2 years resulted in an average $T_{\max }$ value for juvenile 2 - to 3 -year-old plants that was $9.2^{\circ} \mathrm{C}$ lower than the average for mature ( $\sim 30$ years old) plants. A reduction in $\mathrm{CH}$ was also observed in three hybrid rhododendron cultivars clonally propagated by rooted cuttings (ramets) $-T_{\max }$ of 4-year-old ramets was significantly lower than the $T_{\max }$ estimates for the 30- to 40-year-old source plants (ortets). In both the wild $R$. maximum population and the hybrid cultivar group, higher accumulation of a cold-acclimation responsive $25 \mathrm{kDa}$ leaf dehydrin was associated with older plants and higher $\mathrm{CH}$. The feasibility of identifying hardy phenotypes at juvenile period and research implications of age-dependent changes in $\mathrm{CH}$ are discussed.

Keywords: cold acclimation, chronological age, dehydrin, freezing tolerance, physiological age, R. catawbiense, R. fortunei, R. maximum

\section{INTRODUCTION}

Woody perennials typically go through a juvenile period of growth in which they remain vegetative and do not respond to flowering stimuli. This phase of development may last a few weeks in some plants to up to decades in certain shrub and tree species (Kramer and Kozlowski, 1979; Hartmann et al., 1997). Juvenility and the associated phase-change to maturity have strong influences on morphogenesis and tissue differentiation resulting in a number of morphological, physiological, and biochemical alterations in plants (Robinson and Wareing, 1969; Hackett, 1985; Zimmerman et al., 1985; Hackett et al., 1990; Poethig, 1990; Hand et al., 1996). Little is known, however, about the effect of age on abiotic stress tolerance, such as freeze or cold hardiness $(\mathrm{CH})$ of plant tissues.

Improvement in the $\mathrm{CH}$ of woody perennials for their suitability in northern climates has largely been attempted via classical plant breeding. This includes recurrent phenotypic selection of juvenile progenies either based on their winter survival in the field or via laboratory-based $\mathrm{CH}$ tests which may also include evaluation of cold acclimation (CA) — the timing, rate, and degree of $\mathrm{CH}$ increases during fall under inductive short-days and low temperatures. In woody plant breeding programs with long generation times, there is large benefit in time and efficiency if selection can be practiced during the early stages of growth and development for traits that are required at maturity. However, the critical question of how well the expression of adaptive traits during the juvenile stage predicts mature plant phenotypes has received little attention. Anecdotal evidence indicates that field-grown juvenile seedlings of several landscape woody perennials are typically not as cold-hardy as their physiologically mature counterparts (Pellet, 1998; McNamara and Pellet, 2000), however, published literature on the relationship between juvenility, aging, and $\mathrm{CH}$ is scarce. Brown and Bixby (1976) observed that 1-month-old, coldacclimated black locust (Robinia pseudoacacia) seedlings were killed at $0^{\circ} \mathrm{C}$, whereas similarly treated 3 -month-old seedlings could survive $-20^{\circ} \mathrm{C}$. McNamara and Pellet (2000) noted that stem tissues of 10- to 34-month-old Phellodendron sachalinense seedlings (half-sib populations) were hardy to $\sim-5^{\circ} \mathrm{C}$ in early 
October compared to $-14^{\circ} \mathrm{C}$ for the mature female parent growing under similar conditions. Both these studies examined agerelated $\mathrm{CH}$ only in a given year and no systematic study has been undertaken to investigate such changes over multiple years.

Indications of age-dependent $\mathrm{CH}$ phenotypes have been observed in prior research in genus Rhododendron, where the duration of juvenility is approximately 5 years from germination. In one segregating $\mathrm{F}_{2}$ population derived from self-pollination, the mean $T_{\max }$ for 2 - to 3 -year-old progenies was $\sim 12^{\circ} \mathrm{C}$ lower than the mature parent plant grown in similar conditions (Lim et al., 1998b). For a quantitative trait such as $\mathrm{CH}$, this parentoffspring discrepancy in phenotypes is difficult to account for genetically because the expectation for this population is for no change in mean value. Alternatively, it may be explainable by the dependency of $\mathrm{CH}$ on age (chronological and/or physiological).

Knowledge about age-dependent phenotypic expression would be useful to breeders of woody plants who would like to select individuals as early as possible for adaptive traits without having to grow the entire population to maturity. For example, mapping of quantitative trait loci and development of marker assisted selection tools would be most efficient if applied to screenings of young, often juvenile progeny. Success of this application, however, would require that linkage relationships between traits and markers remain consistent as phenotypes change with age. Age-dependent expression of traits may also impact the horticulture industry, which relies heavily on the distribution of relatively young (1- to 2-year-old), vegetatively propagated clones of woody ornamentals, shade or fruit trees, either through rooting stem cuttings or tissue culture. The adaptive phenotypes of these young propagules (ramets) may differ from the older source plants (ortets) from which they are derived.

The present study explores this concept by investigating annual changes in $\mathrm{CH}$ of juvenile seedlings and mature plants over two to three consecutive years in naturally occurring Rhododendron populations as well as breeding populations derived from interspecific hybridization.

\section{MATERIALS AND METHODS TEST PLANTS}

This study involved naturally cold-acclimated plants from four different Rhododendron populations comprising evergreen, non-scaly leaved species within subgenus Hymenanthes (Goetsch et al., 2005). Three of the populations (Table 1) were derived from interspecific cross-pollinations of the cold-hardy native species $R$. catawbiense (using a selected form $R$. catawbiense "Catalgla") with Asian relatives that are less hardy, such as $R$. fortunei and $R$. dichroanthum, for the purpose of producing progeny segregating for $\mathrm{CH}$. Pedigrees for the $\mathrm{F}_{1}, \mathrm{~F}_{2}$, and backcross $(\mathrm{BC})$ populations and the number of progeny are given in Table 1 . All the plants belonging to the hybrid populations and their parents were field grown at The Holden Arboretum's David G. Leach Research Station, Madison, $\mathrm{OH}, \mathrm{USA}$. The parent plants were mature 30to 40 -year-old individuals, with the exception of $R$. dichroanthum "Sonata" which was estimated to be $\sim 10$ years old. Additional comparisons between seedling and mature plants were made using another native species, $R$. maximum, from a population of seedlings naturally growing near the Cooper's Rock State Forest, West Virginia, USA.

\section{COLD HARDINESS DETERMINATION}

For the hybrid populations (Table 1), uniform-sized, currentyear leaves of the same progeny population were screened for two to three consecutive years. In the study of wild $R$. maximum (Table 2), different juvenile and mature individuals (but with approximately similar age difference) were scored over 2 years. Leaves were collected in December each year of the study, at which time they are cold-acclimated, and kept on ice until

Table 2 | Leaf freezing-tolerance ( $T_{\max }$ ) differences between juvenile and mature plants of natural Rhododendron maximum populations.

\begin{tabular}{lcc}
\hline $\boldsymbol{R}$. maximum (natural population) & $\boldsymbol{N}^{\mathbf{z}}$ & Mean $\boldsymbol{T}_{\max }\left({ }^{\circ} \mathbf{C}\right) \pm \mathbf{S E}^{\mathbf{y}}$ \\
\hline Juvenile seedlings & 12 & $-37.6 \pm 1.7^{\mathrm{b}}$ \\
Mature plants & 6 & $-46.8 \pm 1.6^{\mathrm{a}}$
\end{tabular}

${ }^{z} N$, number of plants. Three replicate disks were measured at each treatment temperature.

y Estimated by using Gompertz function fitted to \% adjusted injury data, mean, and SE estimated by replicates (24 leaf disks) using the Jackknife method (Lim et al., 1998a). Mean separation in column by multiple t-test, significant at $P<0.05$. Mean values followed by a different letter in superscript are significantly different $(P<0.05, t$-test).

Table 1 | Cold hardiness estimates $\left(T_{\max }\right)$ of rhododendron cultivars and species used as parents in interspecific hybrid populations and of the resulting seedling populations at various juvenile ages. Additional descriptions are given in Section "Materials and Methods."

\begin{tabular}{|c|c|c|c|c|c|c|c|c|}
\hline \multirow[t]{2}{*}{ Population* } & \multicolumn{2}{|c|}{ Parent $T_{\max }\left({ }^{\circ} \mathrm{C}\right)^{* *}$} & \multirow[t]{2}{*}{$N$} & \multicolumn{5}{|c|}{ Mean progeny $T_{\max } \pm \operatorname{SE}\left({ }^{\circ} \mathrm{C}\right)^{* * *}$} \\
\hline & o & $\sigma^{x}$ & & 1-year-old & 2-year-old & 3-year-old & 4-year-old & 5-year-old \\
\hline $\mathrm{F}_{1}$ & -52.4 & -16.6 & 12 & $-16.1 \pm 0.6^{a}$ & $-22.8 \pm 2.1^{b}$ & - & - & - \\
\hline $\mathrm{F}_{2}$ & -43.0 & & 50 & - & - & $-27.5 \pm 0.8^{a}$ & $-33.9 \pm 0.9^{b}$ & - \\
\hline$B C$ & -43.0 & -32.0 & 20 & - & - & $-19.0 \pm 1.5^{a}$ & $-22.7 \pm 0.6^{b}$ & $-28.3 \pm 0.9^{c}$ \\
\hline \multicolumn{9}{|c|}{${ }^{*} F_{1}=R$. catawbiense "Catalgla" $\times R$. dichroanthum hybrid "Sonata." } \\
\hline \multicolumn{9}{|c|}{$F_{2}=R$. "Ceylon" self-pollinated $(R$. "Ceylon" $=R$. catawbiense "Catalgla" $\times$ R. fortunei). } \\
\hline \multicolumn{9}{|c|}{$B C=R$. "Ceylon" $\times R$. fortunei combined with an equal number of seedlings from the reciprocal cross. } \\
\hline \multicolumn{9}{|c|}{$\begin{array}{l}\text { ** } T_{\max } \text { values reported in Lim et al. (1998b, 1999). The value for } R \text {. dichroanthum is the average of } 1997 \text { and } 1998 T_{\max } \text { determinations, which were not significantly } \\
\text { different (data not shown). }\end{array}$} \\
\hline
\end{tabular}


processed, usually within $24 \mathrm{~h}$. Punched leaf disks $(1 \mathrm{~cm}$ diameter, 24 disks per plant) were slowly cooled, following ice-nucleation at $-1^{\circ} \mathrm{C}$, to eight subfreezing treatment temperatures (three disks per temperature). A temperature treatment range was achieved by placing test tubes containing single disks in a temperaturecontrolled glycol bath (tissues cooled to $-24^{\circ} \mathrm{C}$ ) followed by transfer to a deep freezer $\left(-24\right.$ to $\left.-52^{\circ} \mathrm{C}\right)$ as detailed in Lim et al. (1998b). Cooling rates were $-1^{\circ} \mathrm{C} / 30 \mathrm{~min}$ up to $-10^{\circ} \mathrm{C}$ followed by $\sim-3.5^{\circ} \mathrm{C} / 30 \mathrm{~min}$ thereafter. Freeze-thaw injury was estimated by measuring electrolyte leakage from frozen and overnight thawed tissues as described in Lim et al. (1998a). Ion leakage data transformations, Gompertz functions fitting, and statistical analyses were performed as described by Lim et al. (1998a) to obtain values for $T_{\max }$, the temperature at which the maximum rate of freezing injury occurred and the parameter used to estimate $\mathrm{CH}$. In related studies of Rhododendron by our group, $T_{\max }$ has been shown to correlate highly with $\mathrm{LT}_{50}$, another widely used $\mathrm{CH}$ parameter based on ion-leakage and/or visual observations of freeze-thaw injury in rhododendron leaves (Lim et al., 1998a). Estimated CH in this study is synonymous with leaf freezing tolerance (LFT) in earlier reports.

\section{RESULTS}

\section{F 1 POPULATION (Table 1)}

With the exception of $R$. dichroanthum, the $T_{\max }$ values of the parents used in these crosses have previously been reported (Lim et al., 1998b, 1999). The $T_{\max }$ of the parent $R$. dichroanthum "Sonata" did not vary significantly year to year $(-17.5$ and $-15.7^{\circ} \mathrm{C}$, respectively) with an average $T_{\max }$ of $-16.6^{\circ} \mathrm{C}$. The average $T_{\max }$ for 1-year-old $\mathrm{F}_{1}$ progeny $\left(-16.1^{\circ} \mathrm{C}\right)$ was about the same as the cold-sensitive $R$. dichroanthum parent and $36.3^{\circ} \mathrm{C}$ less hardy than the R. catawbiense parent. The mean $T_{\max }$ in this population increased significantly $\left(6.7^{\circ} \mathrm{C}\right)$ after a second year of growth.

\section{$F_{2}$ POPULATION (Table 1)}

Comparison of 3 - versus 4 -year-old seedlings in this population revealed a significant $6.4^{\circ} \mathrm{C}$ increase in mean $T_{\max }$ in older plants, from $-27.5^{\circ} \mathrm{C}$ at age 3 to $-33.9^{\circ} \mathrm{C}$ at age 4 . Frequency distributions of this population (Figure 1) show a normally distributed curve centered around mean $T_{\max }$ values that shift toward greater $\mathrm{CH}$ after an additional year, although still below the mature parental value of $-43.0^{\circ} \mathrm{C}$ The distribution of $\mathrm{F}_{2}$ phenotypes is consistent with a polygenic control of $\mathrm{CH}$ that has been reported for Rhododendron and other taxa (Guy, 1990; Lim et al., 1998b; Pellet, 1998). The magnitude of the $\mathrm{CH}$ increase varied randomly among $\mathrm{F}_{2}$ individuals and was not correlated with an individual's position in the $\mathrm{CH}$ distribution (data not shown).

\section{BACKCROSS POPULATION (Table 1)}

$T_{\max }$ from 10 progeny in two reciprocal BC populations$R$. fortunei $\times R$. "Ceylon" and $R$. "Ceylon" $\times R$. fortuneiwere annually determined between 1 and 3 years of age. Because the difference between the variances in mean $T_{\max }$ was nonsignificant in the reciprocal crosses ( $F$-test not shown), the $T_{\max }$ data were pooled as a single BC population $(n=20)$. Similar

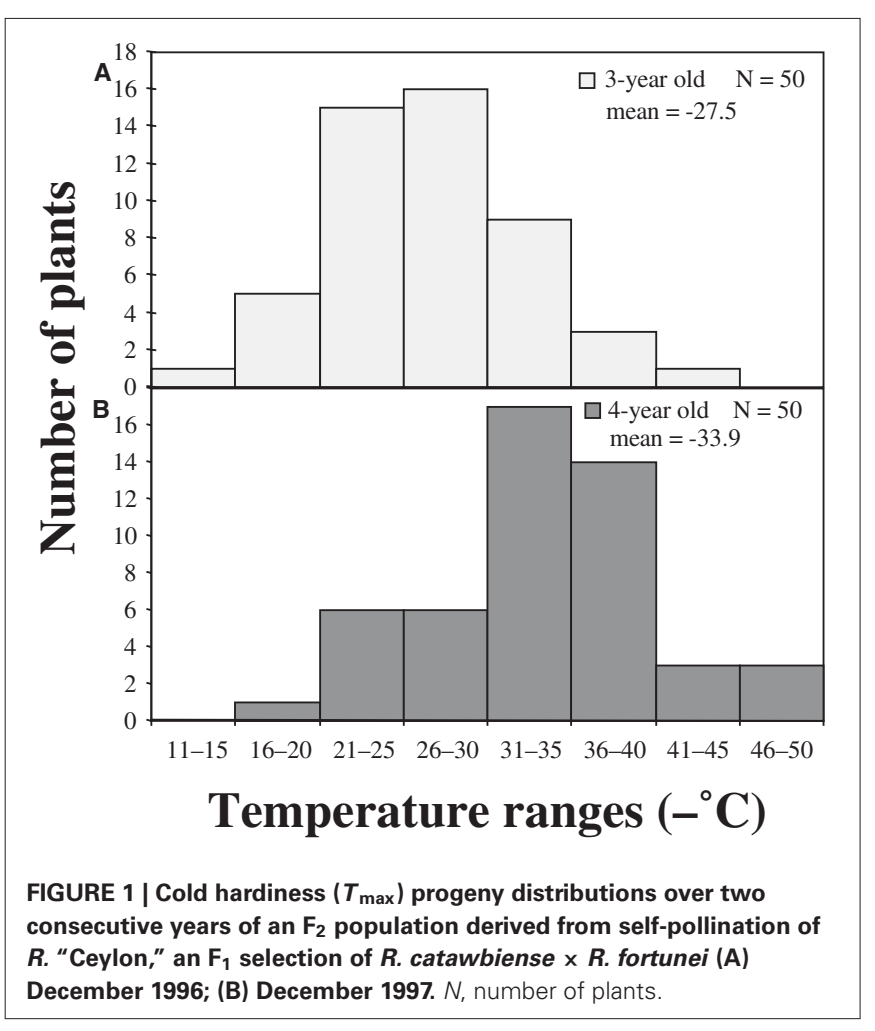

progeny scores from the reciprocal crosses suggest that there is no maternal inheritance determining $\mathrm{CH}$. Average $T_{\max }$ values in the $\mathrm{BC}$ population were 8.5 and $11.2^{\circ} \mathrm{C}$ less hardy than $\mathrm{F}_{2}$ populations of the same age- 3 and 4 years old, respectively. Although both groups are derived from $R$. catawbiense and $R$. fortunei, the BC population has $25 \%$ more contribution from $R$. fortunei, the less cold-hardy parent, than the $\mathrm{F}_{2}$. Like the $\mathrm{F}_{2}$ population, progeny at 3,4 , and 5 years of age varied continuously for $T_{\max }$ (Figure 2), becoming progressively more cold-hardy. The increases in $\mathrm{CH}$ were significant $-3.7^{\circ} \mathrm{C}$ (from 3- to 4-year-old) and $5.6^{\circ} \mathrm{C}$ (from 4- to 5-year-old). By the fifth year, some of the $\mathrm{BC}$ seedlings had set flower buds, an indication of physiological maturity (phase change). However, average $\mathrm{CH}$ in the 5-year-old progeny $\left(-28.2^{\circ} \mathrm{C}\right)$ was still lower than mature $\mathrm{CH}$ of the more cold-sensitive parent, $R$. "Ceylon" $\left(-32.0^{\circ} \mathrm{C}\right)$.

\section{NATURAL POPULATION (Table 2)}

The $T_{\max }$ of juvenile seedlings of the $R$. maximum population was $-37.6^{\circ} \mathrm{C}$, significantly less hardy than older, mature plants in close proximity from the same population, which averaged $-48.6^{\circ} \mathrm{C}$. These results are based on the data from two consecutive years pooled together.

\section{CH RANK CORRELATIONS (Figures 3 and 4)}

In three comparisons, progeny from the same population were numerically ranked based on their $T_{\max }$ values, and regression plots were generated using ranks from consecutive years. In the $\mathrm{F}_{2}$ population (Figure 3 ), there was a significant correspondence 


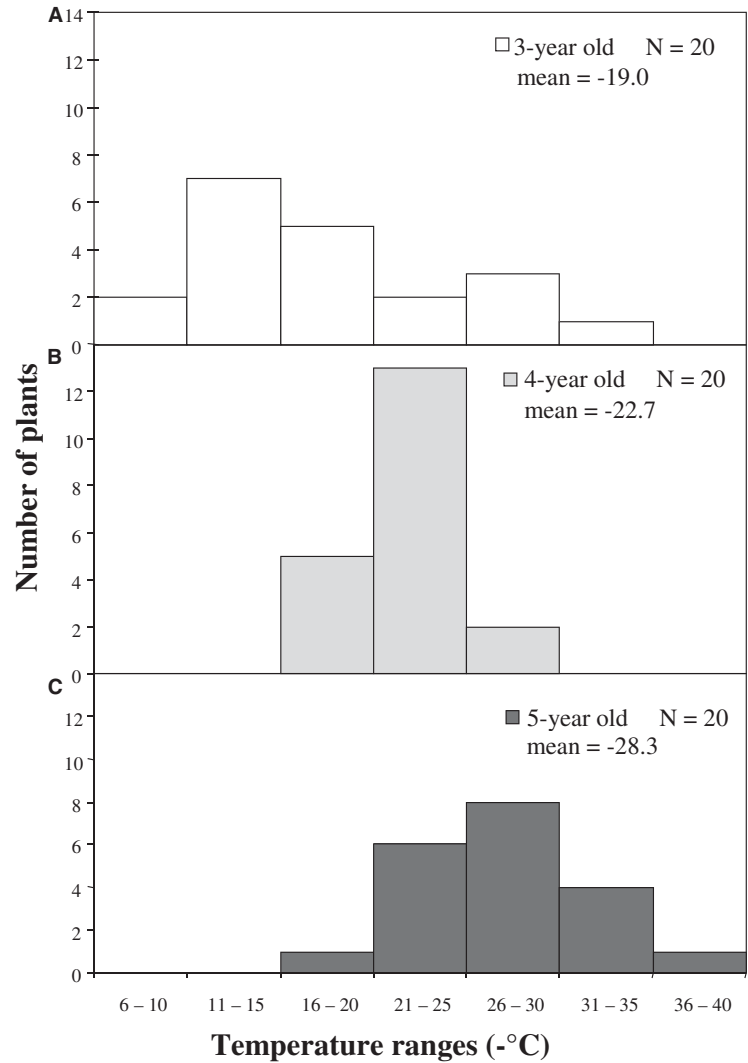

FIGURE 2 | Cold hardiness $\left(T_{\max }\right)$ distribution of a BC population over three consecutive years $(A-C)$.

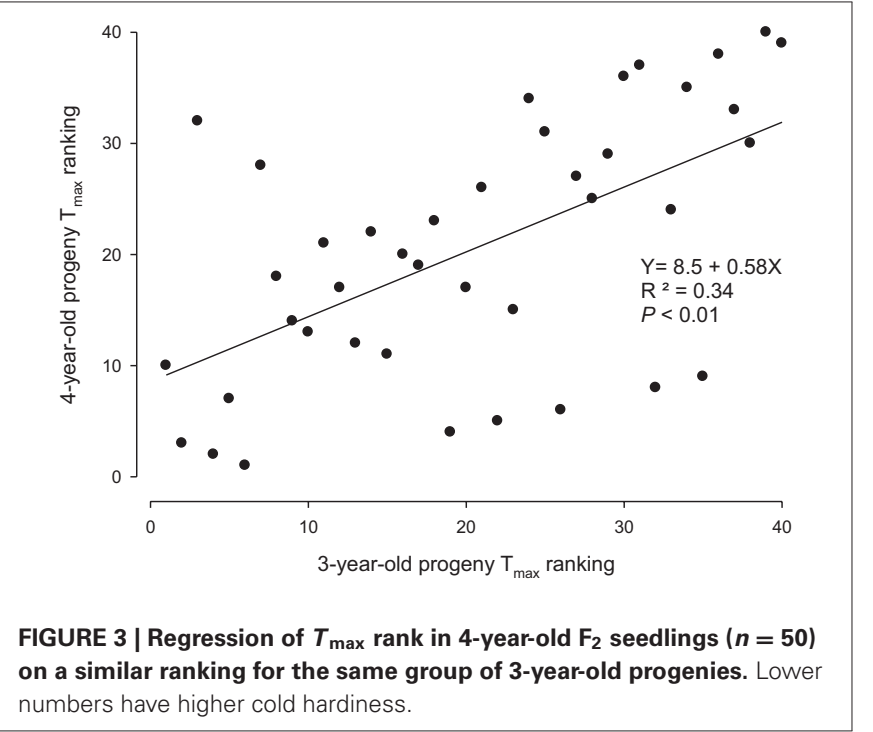

in $T_{\max }$ values at age 3 and age $4\left(R^{2}=0.34, P<0.01\right)$. Similar analysis of the BC population at 3 and 4 years old resulted in no correlation (Figure 4A), but in subsequent years (ages 4 and 5, Figure 4B) the $\mathrm{CH}$ rankings were again significantly correlated $\left(R^{2}=0.52, P<0.01\right)$.
$R$. fortunei $X(R$. fortunei $X R$. catawbiense) BC1 populations $(n=21)$

A
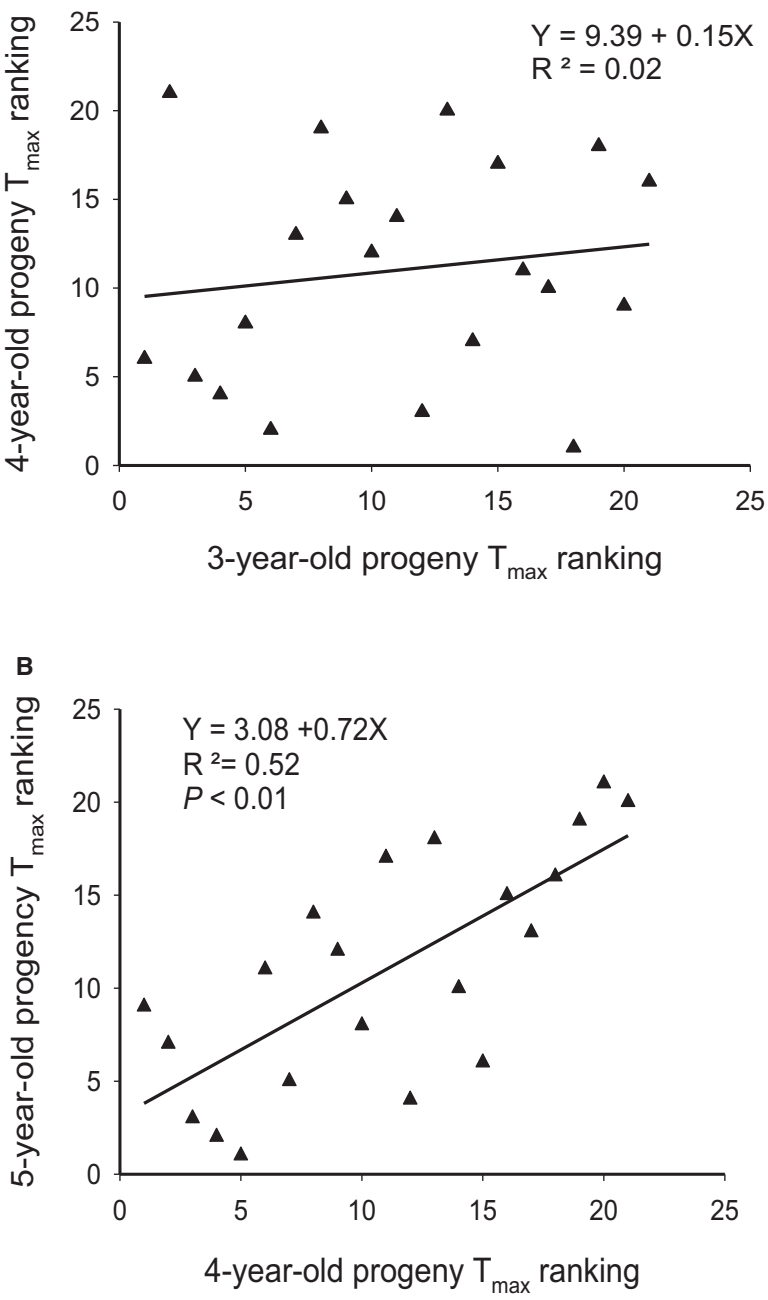

FIGURE 4 | Regression of $T_{\max }$ rankings over 3 years in the BC population [R. fortunei $\times(R$. fortunei $\times R$. catawbiense); $n=21$ ]. (A) Regression of 4- and 3-year-old progeny rankings. (B) Regression of 5- and 4-year-old progeny rankings. Lower numbers have higher cold hardiness.

\section{DISCUSSION}

COLD HARDINESS INCREASES WITH AGE DURING JUVENILE PHASE

Our study used Rhododendron populations segregating for $\mathrm{CH}$ to examine the relationship between juvenile and mature $\mathrm{CH}$ phenotypes. Because $\mathrm{CH}$ is a quantitative trait in Rhododendron and many other taxa (Guy, 1990; Lim et al., 1998b; Pellet, 1998), average progeny phenotypes are expected to be intermediate to the parental values for $\mathrm{CH}$. Our data indicate that the average $T_{\max }$ of 1- to 5-year-old juvenile populations is often lower than the corresponding value of the least hardy parent used in the cross, a result that corresponds with earlier findings (Lim et al., 1998b, 1999). In contrast, $T_{\max }$ values for physiologically mature ( $>10$ year-old) parent plants did not change over the same evaluation period. This suggests that maximal $\mathrm{CH}$ in young Rhododendron offspring may not be fully achieved until after flowering, which 
is approximately 5 years from germination for seedlings grown under natural conditions.

The $\mathrm{CH}$ data from the $\mathrm{F}_{1}, \mathrm{~F}_{2}$, and $\mathrm{BC}$ progenies indicate that juvenile Rhododendron seedlings gain from 3.7 to $6.7^{\circ} \mathrm{C} /$ year in $\mathrm{CH}$, an average of $5.6^{\circ} \mathrm{C}$ year. Since in this study $\mathrm{CH}$ was evaluated in winter (December) using field-grown plants, the increase in $T_{\max }$ most likely reflects a gain in the CA ability, i.e., $\mathrm{CH}$ of CA tissues (winter) minus the $\mathrm{CH}$ at non-acclimated (NA; summer) state. An earlier study of NA- and CA- $T_{\max }$ using a similar set of $\mathrm{F}_{2}$ and $\mathrm{BC}$ Rhododendron populations demonstrated that, of these two components, it is the variation in CA ability rather than NA$\mathrm{CH}$ level that accounts for most of the segregation in $T_{\max }$ values among progeny, and the two components are independent of each other (Lim et al., 1998b).

Cold acclimation in temperate zone woody perennials occurs in two stages: an initial, somewhat smaller increase in the hardiness in response to the inductive short-days in early autumn, followed by a much pronounced gain induced by cold/freezing temperatures in late autumn/winter (Arora et al., 1992). Response to either environmental cue may vary with age. A study of Phellodendron (corktree) seedlings and mature trees in Minnesota determined that $\mathrm{CH}$ in early October (October 9) did not vary among 10- and 36-month-old juvenile seedlings, whereas the older progeny were three times more hardy by October 26 (McNamara and Pellet, 2000). Assuming that the seedlings were experiencing more frosts later in the fall, these data suggest that plant age in Phellodendron has limited effect on the photoperiod response during $\mathrm{CA}$, but a large effect on how plants acclimate in response to cold temperature cues. However, the absence of presumed frosts would suggest that older seedlings (by only 2 years) were perhaps more responsive to short days for CA. Further studies with a wider array of woody plant taxa are needed to determine the extent to which age affects physiological response to the environment during CA.

\section{CORRESPONDENCE OF JUVENILE-MATURE PHENOTYPES}

In woody plant breeding programs, genetic gains over time are slowed if the selection cycle is lengthy. In Rhododendron, the selection cycle is a minimum of 5 years, the time required for most seed-grown progeny to reach flowering, a key ornamental trait. By contrast, the selection cycle in conifer tree breeding is 20-25 years, the time required to reach a harvestable size (yield). Because of the economic significance of timber crops, it is not surprising that the most extensive data on age-age trait correlations derives from long-term (25+ years) experimental forestry plots. Studies of key biometric traits associated with yield, particularly tree height, have demonstrated strong genetic and phenotypic correlations between young (3- to 10-year-old) and mature (20to 25-year-old) trees (Lambeth, 1980; McKeand, 1988). These studies also determined that trait correlation in very young plants aged 1-3 years was much weaker, possibly due to juvenility or the fact that young transplanted seedlings were still adapting to the experimental nursery sites.

The age-age $\mathrm{CH}$ correlations for Rhododendron were determined over a few years of juvenile growth and do not include progeny $\mathrm{CH}$ at maturity. Taken together, the results of progeny rank correlations in the $\mathrm{F}_{2}$ and $\mathrm{BC}$ populations suggest that there is moderate age-age correlation in $\mathrm{CH}$ rankings, and that $\mathrm{CH}$ selections made earlier would correspond reasonably well to selections made a year later. It remains to be determined how well these juvenile $\mathrm{CH}$ estimates predict winter performance at maturity.

Because the oldest population in this study (5-year-old BC seedlings) had an average $T_{\max } \sim 4^{\circ} \mathrm{C}$ below the less hardy parent, it is probable that Rhododendron seedlings do not attain a maximal or full CA ability until after they reach reproductive maturity ( $\sim 5$ years). In contrast, McNamara and Pellet (2000) noted that by late October/late January, the 34 -month-old, juvenile $P$. sachalinense seedlings (but not the younger 10- to 22-monthold seedlings) had nearly similar $\mathrm{CH}$ as their 35 -year-old mature parent, suggesting that attainment of physiological maturity was not a prerequisite for full expression of CA or greater CA ability of 34-month seedlings. The temporal relationship between maximum $\mathrm{CH}$ and flowering is likely to vary widely among woody plant species because of the great variability in the duration of the juvenile phase, which can range from 5 to 40 years among species (Kramer and Kozlowski, 1979). For example, tree genera such as Quercus (oak) and Fagus (beech) contain species with very long juvenile phases (30+ years) and it is likely in those cases that full, adult stage $\mathrm{CH}$ levels are attained prior to flowering.

\section{MECHANISMS FOR AGE-DEPENDENT PHENOTYPES}

Very few studies have examined the mechanisms for agedependent expression of adaptive traits at the whole plant, cellular, or molecular scales. There is some evidence for an association between changes in gene expression and leaf morphology/physiology during the juvenile-to-mature phase transition in woody perennials. For example, proline-rich-protein (PRP) gene is expressed more strongly in mature petioles than juvenile ones while the gene for dihydroflavonol reductase (DFR), an enzyme needed for anthocyanin production, is only present in juvenile petioles in English ivy (Murray and Hackett, 1991; Woo et al., 1994). Similarly, in both larch and English ivy, the expression of chlorophyll $a / b$ binding protein (cab) gene decreases with maturation (Hutchison et al., 1990).

In an earlier report, levels of $25 \mathrm{kDa}$ dehydrin (DHN) were higher (up to a 2.2-fold increase) in mature Rhododendron cultivars (ortets) than in 2- to 3-year-old clones (ramets) propagated as rooted cuttings from the mature plants (Lim et al., 1999; Figure 5). Similarly, $25 \mathrm{kDa}$ DHN levels were 2.4-fold higher in leaves from mature wild plants of $R$. maximum than in juvenile seedlings growing nearby (Figure 5). This provides evidence of changes in gene expression associated with age-dependent $\mathrm{CH}$ phenotypes, because the younger clones and juvenile seedlings were also less cold-hardy than mature plants. DHN proteins, hydrophilic members of group 2 LEA family (Close, 1996), have been widely implicated to have a role in CA process and conferring protection against freeze-desiccation (Kosová et al., 2007). Furthermore, prior research established a significant correlation between the abundance of a $25-\mathrm{kDa}$ DHN and CA ability of several Rhododendron species (Marian et al., 2004) and populations (Lim et al., 1999). At present, however, a causal relationship between plant age and $25 \mathrm{kDa}$ DHN accumulation has not been established. 


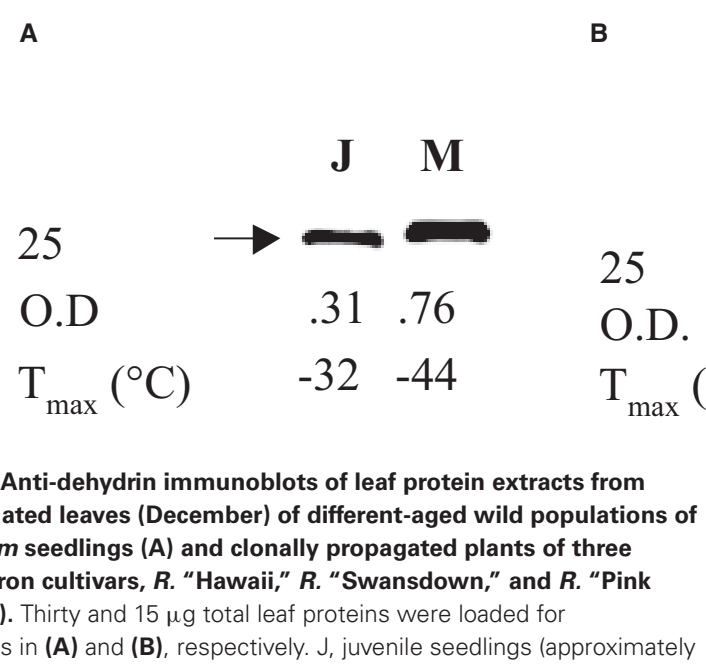

FIGURE 5 | Anti-dehydrin immunoblots of leaf protein extracts from cold-acclimated leaves (December) of different-aged wild populations of $\boldsymbol{R}$. maximum seedlings (A) and clonally propagated plants of three rhododendron cultivars, $R$. "Hawaii," $R$. "Swansdown," and $R$. "Pink Parasol" (B). Thirty and $15 \mu \mathrm{g}$ total leaf proteins were loaded for immunoblots in (A) and (B), respectively. J, juvenile seedlings (approximately

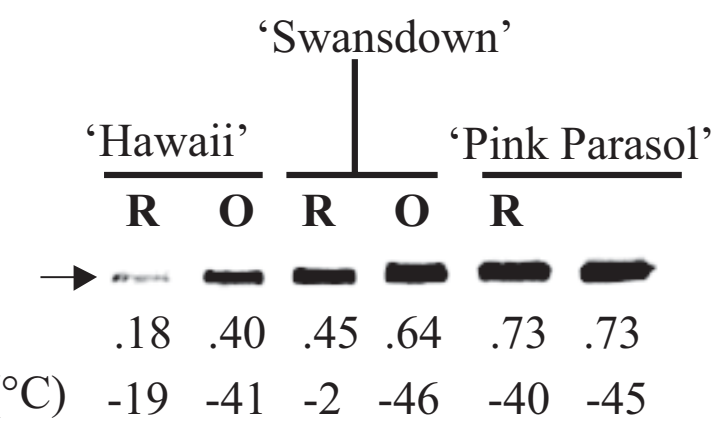

2- to 3-year-old); $M$, mature plants (approximately 30-year-old); $\mathrm{R}$, ramet (approximately 4-year-old plants clonally propagated from the 30- to 40-year-old ortets); O, ortet; OD, optical densities (quantitative parameter for the band density); $T_{\max }$, quantitative measure of leaf-freezing-tolerance. Arrow points to a band of dehydrin protein of $25 \mathrm{kDa}$ (this figure is adapted from Lim et al., 1999).
It has also been suggested that the relative concentrations (ratios) of phytohormones-abscisic acid (ABA), gibberellic acid (GA), auxins, and cytokinins_play a major role in regulating juvenile-to-mature phase transition (Haffner et al., 1991). The role of ABA has been well established as one of the key molecules in the signal cascade for CA in both herbaceous and woody species (Gusta et al., 2005) while other research suggests that GA is a negative regulator of cold-tolerance (Pieniazek and Holubowicz, 1973; Shan et al., 2007). Investigation into the biochemical or molecular changes vis-à-vis age-dependent changes in $\mathrm{CH}$ was not the focus of the present study, however, this area is ripe for in-depth research, including the study of shifts in hormonal balance and expressions of cold-regulated (cor) genes that have particularly been implicated in cold-stress tolerance.

While exploring putative mechanisms for age-dependent changes in $\mathrm{CH}$ (or other adaptive traits) it should be recognized that the overall size of a plant also increases with age, and, therefore, it may be difficult to separate age responses from those potentially associated with biomass accumulation. Because our estimates of $\mathrm{CH}$ are based on leaf freezing assays, age-dependent leaf traits could affect the results. For example, earlier work with Rhododendron leaves demonstrated that both leaf and cuticle thickness increased during CA and that a coldhardy species, $R$. catawbiense, had a thicker cuticle than a less hardy species, R. ponticum (Wang et al., 2008). Huner et al. (1981) and Stefanowska et al. (1999) have also noted an association between CA and increased leaf-thickness, presumably due to cell wall thickness.

Our study used current year Rhododendron leaves to estimate $\mathrm{CH}$ on plants of different age and biomass. Increased leaf $\mathrm{CH}$ in older plants may be due in part to translocation of metabolites involved in secondary cell wall formation and lignin formation, originating from older wood cells in the stems and roots. Transcriptome comparisons of juvenile versus mature wood in Pinus (Li et al., 2011) has identified greater expression of genes related to cellulose synthesis and lignification in mature wood, which would make the component carbohydrates and phenols more readily available to new tissue in older plants. Alternatively, the increase in $\mathrm{CH}$ observed in new leaves on older plants may result from a high source:sink ratio that makes more nutrients available for stress responses. Both the biomass and metabolite explanations for age-dependent $\mathrm{CH}$ are intriguing but as yet untested hypotheses.

Long-lived woody plants appear to have the chemistry and adaptability to survive many types of biotic and abiotic stresses. However, despite their economic and ecological importance, particularly at maturity and beyond, there are few chronologies of stress tolerance or studies of how (or whether) these tolerances are maintained over long periods of time. It is not known, for instance, whether the observed decline in photosynthesis and stomatal conductance with increased tree age (Bond, 2000) is associated with a decline in $\mathrm{CH}$ or other types of stress tolerance. A better understanding of age-related $\mathrm{CA}$ and $\mathrm{CH}$ in woody plants would be of practical significance to plant breeders, tree crop producers, and foresters, and could assist ecologists in assessing the adaptability of long-lived plant communities to climate change.

\section{ACKNOWLEDGMENTS}

This article is dedicated to the memory of Chon-Chong (Kenny) Lim, with deep appreciation and admiration of his efforts, skills, and delightful character. We sincerely thank Mohd. Salleh Daim and Hatice S. Gulen for their technical assistance on evaluating the Rhododendron $\mathrm{CH}$.

\section{REFERENCES}

Arora, R., Wisniewski, M. E., and Scorza, R. (1992). Cold acclimation in genetically related (sibling) deciduous and evergreen peach (Prunus persica [L.] Batsch). I. Seasonal changes in cold hardiness and polypeptides of bark and xylem tissues. Plant Physiol. 99, 1562-1568. doi: 10.1104/pp.99.4. 1562

Bond, B. J. (2000). Age-related changes in photosynthesis of woody plants. Trends Plant Sci. 5, 349-353. doi: 10.1016/S1360-1385(00)01691-5

Brown, G. N., and Bixby, J. A. (1976). Relationship between black locust seedling age and induction of cold hardiness. For. Sci. 22, 208-210.

Close, T. J. (1996). Dehydrins: emergence of a biochemical role of a family of plant dehydration proteins. Physiol. Plant. 97, 795-803. doi: 10.1111/j.13993054.1996.tb00546.x 
Goetsch, L. A., Eckert, A. J., and Hall, B. D. (2005). The molecular systematics of Rhododendron (Ericaceae): a phylogeny based upon RPB2 gene sequences. Syst. Bot. 30, 616-626. doi: 10.1600/0363644054782170

Gusta, L. V., Trischuk, R., and Weiser, C. J. (2005). Plant cold acclimation: the role of abscisic acid. J. Plant Growth Regul. 24, 308-318. doi: 10.1007/s00344-0050079-x

Guy, C. L. (1990). Cold acclimation and freezing stress tolerance: role of protein metabolism. Annu. Rev. Plant Physiol. Plant Mol. Biol. 41, 187-223. doi: 10.1146/annurev.pp.41.060190.001155

Hackett, W. P. (1985). Juvenility, maturation, and rejuvenation in woody plants. Hortic. Rev. 7, 109-155. doi: 10.1002/9781118060735.ch3

Hackett, W. P., Murray, J. R., Woo, H. H., Stapfer, R. E., and Geneve, R. (1990). "Cellular, biochemical and molecular characteristics related to maturation and rejuvenation in woody species," in Plant Aging: Basic and Applied Approaches, eds R. Rodriguez, R. S. Tames, and D. J. Durzan (New York: Plenum Press), $147-152$.

Haffner, V. F., Enjalric, F., Lardet, L., and Carron, M. P. (1991). Maturation of woody plants: a review of metabolic and genomic aspects. Ann. For. Sci. 48, 615630. doi: 10.1051/forest:19910601

Hand, P., Besford, R. T., Richardson, C. M., and Peppitt, S. D. (1996). Antibodies to phase related proteins in juvenile and mature Prunus avium. J. Plant Growth Regul. 20, 25-29. doi: 10.1007/BF00024053

Hartmann, H. T., Kester, D. E., Davies, T. T., and Geneve, R. L. (1997). Plant Propagation: Principles and Practices, 6th Edn. Upper Saddle River, NJ: Prentice Hall, 29.

Huner, N. P. A., Palta, J. P., Li, P. H., and Carter, J. V. (1981). Anatomical changes in leaves of Puma rye in response to growth at cold-hardening temperatures. Bot. Gaz. 142, 55-62. doi: 10.1086/337196

Hutchison, K. W., Sherman, C. B., Weber, J., Smith, S. S., Singer, P. B., and Greenwood, M. S. (1990). Maturation in larch. II. Effects of age on photosynthesis and gene expression in developing foliage. Plant Physiol. 94, 1308-1315. doi: 10.1104/pp.94.3.1308

Kosová, K., Vítámvás, P., and Prášil, I. T. (2007). The role of dehydrins in plant response to cold. Biol. Plant. 51, 601-617. doi: 10.1007/s10535-007-0133-6

Kramer, P. J., and Kozlowski, T. T. (1979). Physiology of Woody Plants, 2nd Edn. New York: Academic Press, 114-117.

Lambeth, C. C. (1980). Juvenile-mature correlations in Pinaceae and implications for early plant selection. For. Sci. 26, 571-580.

Li, X., Wu, H. X., and Southerton, S. G. (2011). Transcriptome profiling of wood maturation in Pinus radiata identifies differentially expressed genes with implications in juvenile and mature wood variation. Gene 487, 62-71. doi: 10.1016/j.gene.2011.07.028

Lim, C. C., Arora, R., and Townsend, E. D. (1998a). Comparing Gompertz and Richards functions to estimate freezing injury in Rhododendron using electrolyte leakage. J. Am. Soc. Hortic. Sci. 123, 246-252.

Lim, C. C., Krebs, S. L., and Arora, R. (1998b). Genetic study of freeze-tolerance in Rhododendron populations: implications for cold hardiness breeding. J. Am. Rhododendron Soc. 52, 143-148.

Lim, C. C., Krebs, S. L., and Arora, R. (1999). A 25-kDa dehydrin associated with genotype- and age-dependent leaf freezing-tolerance in Rhododendron: a genetic marker for cold hardiness? Theor. Appl. Genet. 99, 910-918. doi: 10.1007/s001220051312

Marian, C. O., Krebs, S. L., and Arora, R. (2004). Dehydrin variability among Rhododendron spp: a $25 \mathrm{kDa}$ dehydrin is highly conserved and associated with cold acclimation across a wide array of species. New Phytol. 161, 773-780. doi: 10.1111/j.1469-8137.2003.01001.x
McKeand, S. (1988). Optimal age for family selection for growth in genetic tests of loblolly pine. For. Sci. 34, 400-411.

McNamara, S., and Pellet, H. (2000). Cold hardiness of Phellodendron sachalinense Friedr. Schmidt seedlings increases with age. HortScience 35, 304-305.

Murray, J. R., and Hackett, W. P. (1991). Dihydroflavonol reductase activity in relation to differential anthocyanin accumulation in juvenile and mature phase Hedera helix L. Plant Physiol. 97, 343-351. doi: 10.1104/pp.97. 1.343

Pellet, H. (1998). "Breeding of cold hardy woody landscape plants," in Plant Cold Hardiness: Molecular Biology, Biochemistry, and Physiology, eds P. H. Li and T. H. H. Chen (New York: Plenum Press), 317-324.

Pieniazek, J., and Holubowicz, T. (1973). The effect if abscisic acid and gibberellic acid on the cold hardiness of apple seedlings and explants. Acta Hortic. 34, 247-250.

Poethig, R. S. (1990). Phase change and the regulation of shoot morphogenesis in plants. Science 250, 923-930.

Robinson, L. W., and Wareing, P. F. (1969). Experiments on the juvenile-adult phase change in some woody species. New Phytol. 68, 67-78.

Shan, D. P., Huang, J. G., Yang, Y. T., Guo, Y. H., Wu, C. A., Yang, G. D., et al. (2007). Cotton GhDREB1 increases plant tolerance to low temperature and is negatively regulated by gibberellic acid. New Phytol. 176, 70-81. doi: 10.1111/j.14698137.2007.02160.x

Stefanowska, M., Kuras, M., Kubacka-Zebalska, M., and Kacperska, A. (1999). Low temperature affects pattern of leaf growth and structure of cell walls in winter oilseed rape (Brassica napus L., var. oleifera L.). Ann. Bot. 84, 313-319. doi: 10.1006/anbo.1999.0924

Wang, X., Arora, R., Horner, H. T., and Krebs, S. L. (2008). Structural adaptations in overwintering leaves of thermonastic and nonthermonastic Rhododendron species. J. Am. Soc. Hortic. Sci. 133, 768-776.

Woo, H. H., Hacket, W. P., and Das, A. (1994). Differential expression of a chlorophyll $a / b$ binding protein gene and a proline rich protein gene in juvenile and mature phase English ivy (Hedera helix). Physiol. Plant. 92, 69-78. doi: 10.1111/j.1399-3054.1994.tb06656.x

Zimmerman, R. H., Hackett, W. P., and Pharis, R. P. (1985). "Hormonal aspects of phase change and precocious flowering," in Hormonal Regulation of Plant Development III, New Series 11, eds R. P. Pharis and D. M. Reid (Berlin: Springer-Verlag), 79-115.

Conflict of Interest Statement: The authors declare that the research was conducted in the absence of any commercial or financial relationships that could be construed as a potential conflict of interest.

Received: 27 August 2014; paper pending published: 11 September 2014; accepted: 23 September 2014; published online: 16 October 2014.

Citation: Lim C-C, Krebs SL and Arora $R$ (2014) Cold hardiness increases with age in juvenile Rhododendron populations. Front. Plant Sci. 5:542. doi: 10.3389/fpls.2014.00542

This article was submitted to Functional Plant Ecology, a section of the journal Frontiers in Plant Science.

Copyright (c) 2014 Lim, Krebs and Arora. This is an open-access article distributed under the terms of the Creative Commons Attribution License (CC BY). The use, distribution or reproduction in other forums is permitted, provided the original author(s) or licensor are credited and that the original publication in this journal is cited, in accordance with accepted academic practice. No use, distribution or reproduction is permitted which does not comply with these terms. 